\title{
Visual field loss in schizophrenia: evaluation of magnocellular pathway dysfunction in schizophrenic patients and their parents
}

This article was published in the following Dove Press journal:

Clinical Ophthalmology

28 May 2013

Number of times this article has been viewed

\section{Carolina Pelegrini Barbosa Gracitelli' \\ Fabiana Benites Vaz de Lima $^{2,3}$ \\ Rodrigo A Bressan ${ }^{2,3}$ Augusto Paranhos Junior ${ }^{1}$ \\ 'Department of Ophthalmology, Federal University of São Paulo (UNIFESP), São Paulo, SP, Brazil; ${ }^{2}$ LiNC - Interdisciplinary Laboratory of Neuroimaging and Cognition, Department of Psychiatry, Federal University of São Paulo (UNIFESP), São Paulo, SP, Brazil; ${ }^{3}$ PROESQ - Schizophrenia Program, Federal University of São Paulo (UNIFESP), São Paulo, SP, Brazil}

Purpose: We sought to evaluate the visual pathway deficits in schizophrenic patients, compared with their parents and healthy controls, using Matrix frequency doubling technology (FDT) perimetry. Matrix FDT is an ophthalmic test used to detect visual field loss.

Method: A total of 13 patients, 13 parents, and 12 healthy controls were enrolled in the study. Participants were subjected to Matrix FDT perimetry in a single test session. We analyzed the mean deviation for each eye and used a generalized estimated equation to evaluate differences among the groups and correct the dependency between the eyes.

Results: The global mean deviation (presented as the mean of both eyes) was significantly lower in the schizophrenic patients than in their parents or controls. Analysis of the general sensitivity of the fibers crossing the optic chiasm showed a difference between the groups $(P=0.006)$, indicating that the sensitivity of the fibers crossing the optic chiasm was lower than those which did not cross. But when we analyzed the specific groups, the difference between the fibers was not considerable. Comparison of the right and left hemispheres showed that general sensitivity was lower for the left hemisphere, but when we analyzed specific groups, the difference was not significant $(P=0.29)$.

Conclusion: These findings are suggestive of a lower global sensitivity in schizophrenic patients and their parents compared with controls. This difference may be an endophenotype of schizophrenia. The present study adds to a growing body of research on early-stage visual processing deficits in schizophrenia.

Keywords: schizophrenic patients, visual processing, endophenotype, frequency doubling technology

\section{Introduction}

Schizophrenic patients exhibit not only cognitive dysfunctions, such as memory and attention deficits, ${ }^{1,2}$ but also deficits in basic sensory processing. ${ }^{3-6}$ In particular, disturbances of the visual system have been documented, in studies employing diverse methodologies, including psychophysical tests (eg, visual masking procedures), contrast sensitivity tests, visually evoked potentials, and smooth pursuit tracking tasks. ${ }^{7-9}$

Visual processing research in human and nonhuman primates has identified two separate but interacting visual subsystems. ${ }^{10,11}$ the magnocellular (M) pathway, which is primarily responsible for processing information about location and motion, and the parvocellular pathway, which is primarily responsible for processing information about detail and color. ${ }^{12}$ There is evidence to suggest that the M pathway is hypoactive in schizophrenia. For example, studies using electroencephalography (EEG) have Barbosa Gracitelli

Federal University of São Paulo (UNIFESP/EPM), Botucatu Street, 82I Vila Clementino, São Paulo, 04023-062, Brazil

Tel +55 I I 50852020

Fax +55 I| 5085 203 |

Email carolepm@gmail.com 
shown reduced signal amplitudes in the posterior cortical regions along the $\mathrm{M}$ pathway in schizophrenic patients, with relatively normal activation along the pathway. ${ }^{13-15}$ Likewise, Braus et $\mathrm{al}^{16}$ using functional magnetic resonance imaging (fMRI), showed M pathway hypoactivation (particularly in the right hemisphere) in schizophrenic patients but found no evidence of abnormal functioning of the pathway, and Bedwell et $\mathrm{al}^{17}$ reported evidence of right hemisphere $\mathrm{M}$ pathway hypoactivity in nonpsychotic first-degree relatives of schizophrenics, using fMRI. ${ }^{17}$

While visual dysfunctions in schizophrenia have been described in the literature, ${ }^{13,14,18}$ their potential significance as endophenotypes of the disorder remains unclear. Gottesman and Gould ${ }^{19}$ defined the endophenotypes of an illness as having the following characteristics: they cosegregate with the illness in affected families; are associated with the illness; are present in unaffected biological relatives at a higher rate than in the general population; are heritable; and are detectable in remitted patients. Deficits in working memory, executive function, sustained attention, sensory gating, smooth pursuit eye movements, verbal memory, and language production all have been identified as endophenotypes of schizophrenia. ${ }^{19}$

Frequency doubling technology (FDT) is an automated tool that can detect alterations in contrast sensitivity and visual field defects. ${ }^{20}$ FDT is used in glaucoma disease. ${ }^{21}$ This technique uses an optical illusion called "frequency doubling," which occurs when an achromatic, low spatial frequency sinusoidal grating undergoes counter-phased flickering at a high temporal frequency, resulting in an apparent doubling of the spatial frequency of the grating. ${ }^{20,22,23}$ Processing of the FDT signal is thought to involve the activation in the $\mathrm{M}$ pathway and visual association areas. ${ }^{23,24}$ So, the FDT can be used to assess retinal ganglion cell function and provides a means to study deficits of early visual processing in schizophrenia, and this can have some laterality, as described by Bedwell et al. ${ }^{17}$

In this study, we aimed to evaluate initial visual processing (perception of a stimulus by ganglion cells) in schizophrenic patients, as compared with their parents and healthy controls, using a Matrix FDT perimetry device to evaluate and follow the evolution of the visual field.

\section{Methods}

\section{Participants}

Thirteen schizophrenic patients from the Schizophrenia Program of the Federal University of São Paulo participated in the study. The mean age of study patients was $37.85 \pm$ 8.42 years (46\% male and $54 \%$ female). All patients were outpatients with a diagnosis of schizophrenia, according to DSM-IV. The diagnosis of schizophrenia was confirmed by a trained psychiatrist, using the Structured Clinical Interview for DSM-IV. All patients were refractory to treatment with antipsychotics, and they were taking clozapine (average dose $300 \mathrm{mg} /$ day). The study also included 13 parents (mother or father) of the patients (mean age was 60.92 \pm 9.83 years; $23 \%$ male and $77 \%$ female) and 12 healthy controls (volunteers recruited from among the hospital staff and students at the Federal University of São Paulo). The mean age of the control group was $38.46 \pm 14.79$ years; $58 \%$ male and $42 \%$ female.

Patients included for study had a confirmed diagnosis of schizophrenia for at least 10 years and had been taking antipsychotic drugs or other psychotropic agents (eg, benzodiazepines) for at least 6 months at the time of the study. Other inclusion criteria for the schizophrenic patients were as follows: good vision (visual acuity greater than 20/60 in both eyes, as measured with the Snellen chart and greater than $20 / 30$ in both eyes after refraction correction), normal optic nerve (cup disc ratio less than 0.6), lower intraocular pressure of $20 \mathrm{mmHg}$, as measured with the Goldmann tonometer, and normal biomicroscopic examination, assessed using a slit lamp. Exclusion criteria for the patients included a history of drug or alcohol abuse or dependence, the presence of any neurological disease that could affect performance on the test (eg, cerebral palsy), or the presence of any disease affecting the visual field (eg, pituitary lesions or diabetic retinopathy).

The inclusion criteria for the parent and control groups consisted of the same ophthalmologic criteria listed above for the patients, as well as a score of less than or equal to seven positive answers on the Self-Reporting Questionnaire-20 mental status assessment. The exclusion criteria for these groups included the presence of psychiatric illness (in the control group), substance abuse, the presence of a disease affecting the visual field (eg, pituitary lesions or diabetic retinopathy), or the presence of any systemic disease potentially affecting the visual system (eg, multiple sclerosis).

All subjects signed a consent form that was approved by the local human research ethics committee. The research was conducted in a manner consistent with the principles outlined in an internationally recognized standard for the ethical conduct of research. The research was adhered to the tenets of the Declaration of Helsinki and was approved by the Institutional Review Board of the Federal University of São Paulo. 


\section{Apparatus}

FDT perimetry was measured using the Humphrey ${ }^{\circledR}$ Matrix 800 FDT instrument (Carl Zeiss Meditec, Jena, Germany). ${ }^{25-27}$

\section{Clinical evaluation}

All participants received an ophthalmic examination that included tests of visual acuity, refraction, and biomicroscopy of the anterior chamber, as well as measurement of intraocular pressure and fundus examination.

Participants received instructions about performing the Matrix FDT test. They then were screened for 30 seconds, during which time they learned to recognize the stimuli and adapted to the test conditions. Stimuli were presented on the computer screen and participants were asked to press a button when they saw a gray square. All participants were tested with a standard FDT 24-2 visual field contrast sensitivity threshold exam protocol (programmed into the device), which evaluates 55 visual field regions in the right eye, followed by 55 regions in the left eye. ${ }^{28}$ This test provides a single measure of the contrast sensitivity threshold (in decibels) at each of the 110 regions, using a maximum likelihood threshold strategy (zippy estimation by sequential testing $[\mathrm{ZEST}]) .{ }^{29}$ The Matrix FDT 24-2 exam featured 24-degree coverage with a stimulus size of 5 degrees, a spatial frequency of 0.5 cycles per degree, and a temporal frequency of $18 \mathrm{~Hz} .^{28}$ In addition to the threshold values for each region, two summary measures of general contrast sensitivity across the visual field were also reported, the mean deviation and pattern standard deviation. The mean deviation is a measure of the overall contrast sensitivity in each eye, while the pattern standard deviation indicates how each of the 55 visual field test locations deviates from the expected value from the age-adjusted normative database, after adjustment for any general reduction or enhancement of contrast sensitivity. In addition, because the 24-2 threshold visual field test is iterative, the exam duration also potentially represents a general measure of contrast sensitivity performance. Finally, reliability tests were completed, including estimations of the fixation errors, false positive errors, and false negative errors. Fixation errors were tested by a stimulus of $50 \%$ contrast in the location of the blind spot, ${ }^{30}$ which should not be detected if proper fixation is maintained. False positive errors were tested by presenting stimuli at $0 \%$ contrast, with any responses to these stimuli considered false positive errors. False negative errors were tested by presenting stimuli at $100 \%$ contrast, so that no response would be a false negative error. ${ }^{20,28}$ The 24-2 test included ten fixation error trials, ten false positive trials, and six false negative trials. If the test was unreliable at first, it could be repeated a second time.

\section{Statistical analysis}

Descriptive analysis was used to present the demographic and clinical data. We analyzed global sensitivity as well as cerebral hemisphere sensitivity by comparing the mean deviation (MD) of the schizophrenic patient group, parent group, and control group using analysis of variance (ANOVA). We also analyzed the sensitivity of fibers that cross the optic chiasm (decussating fibers) and those that do not (nondecussating fibers), using the same test.

The MD was used to assess global sensitivity. The right hemisphere analysis included the mean sensitivity of the right temporal and left nasal hemifields. The left hemisphere analysis included the mean sensitivity of the left temporal and right nasal hemifields. The sensitivity analysis for decussating fibers included the nasal hemifields of both sides, and for nondecussating fibers included the temporal hemifields of both sides. Statistical analyses were performed using the SPSS statistical package 17.0 (IBM, Armonk, NY, USA).

\section{Results}

The sociodemographic and ophthalmic characteristics of the participants are described in Table 1. All the patients were outpatients with diagnosis of schizophrenia according to the DSM-IV. All patients were refractory to treatment with antipsychotics, and they were taking clozapine (average dose $300 \mathrm{mg} /$ day). The majority of the patients were Caucasian (ten out of 13), and three were Asians. The mean duration of disease was 15 years. None in the group was working. The range education was 5 to 10 years. The visual acuity of the whole group was higher than $20 / 60$, as tested by the Snellen chart, and higher than 20/30 after refraction. Intraocular pressure was normal (less than $20 \mathrm{mmHg}$ ) for all groups. Group differences in intraocular pressure were not statistically significant and were less than $2 \mathrm{mmHg}$, which is not clinically relevant and cannot affect the FDT results. Five patients in the schizophrenic group were excluded at the first test, three of whom exhibited $>20 \%$ loss of fixation and two of whom exhibited both $>20 \%$ loss of fixation and $>33 \%$ false negatives. Afterwards, upon retest, they were included once again because the indices were acceptable.

Table 2 presents the global mean sensitivity values in the Matrix FDT test. The MD values in the schizophrenic patients and their parents were significantly lower than those 
Table I Sociodemographic and ophthalmic characteristics of the study participants

\begin{tabular}{|c|c|c|c|c|}
\hline & $\begin{array}{l}\text { Healthy } \\
\text { controls } \\
(n=12)\end{array}$ & $\begin{array}{l}\text { Parents } \\
(n=13)\end{array}$ & $\begin{array}{l}\text { Schizophrenic } \\
\text { patients } \\
(n=13)\end{array}$ & $P$-value \\
\hline \multirow[t]{2}{*}{ Gender } & 7 male & 3 male & 6 male & $P<0.001$ \\
\hline & 5 female & 10 female & 7 female & \\
\hline $\begin{array}{l}\text { VA } \\
\text { (logMAR) }\end{array}$ & $0.53(0.08)$ & $0.35(0.11)$ & $0.33(0.12)$ & $P=0.097^{*}$ \\
\hline $\begin{array}{l}\text { Age } \\
\text { (years) }\end{array}$ & 38.46 (14.79) & $60.92(9.83)$ & $37.85(8.42)$ & $\mathrm{P}<0.00 \mathrm{I}^{\dagger}$ \\
\hline $\begin{array}{l}\text { IOP } \\
(\mathrm{mmHg})\end{array}$ & I5.83 (2.59) & $16.23(2.20)$ & $16.46(2.81)$ & $P=0.83$ \\
\hline Refraction & $-0.64(1.02)$ & $-0.73(2.90)$ & $-0.5 \mathrm{I}(2.80)$ & $P=0.88$ \\
\hline
\end{tabular}

Notes: Data are presented as means, with standard deviations in parentheses. Acuity in $\log M A R$. Refraction = spherical equivalent. . Statistically significant difference between parents and schizophrenic patients and healthy controls; *no statistically significant difference between healthy controls and schizophrenic patients.

Abbreviations: IOP, intraocular pressure; VA, visual acuity ; logMAR, logarithm of the minimum angle of resolution.

in the control group, but did not differ from one another. Figure 1 shows the distributions of the MD values in the three groups, as box plots.

Analysis of the fibers crossing the optic chiasm between the groups $(P=0.006)$ showed a difference in general sensitivity, indicating that the sensitivity of the fibers crossing the optic chiasm was lower than those which did not cross, but when we analyzed the specific groups, the difference between the fibers was not considerable (Figure 2).

Analysis of the right and left hemispheres showed the general sensitivity was lower for the left hemisphere, but when we analyzed specific groups, this difference was not significant $(P=0.29)$ (Figure 3).

Global MD values were not impacted by age, gender, length of time with a diagnosis of schizophrenia, or the use of antipsychotics.

\section{Discussion}

Few physiological studies have examined M pathway functioning in schizophrenia. Three studies using EEG reported reduced signal amplitude in the posterior cortical regions along the M pathway in persons with schizophrenia, with normal activation in the P pathway. ${ }^{13-15}$ One study used fMRI and reported hypoactivation of the M pathway (particularly in the right hemisphere) in persons with schizophrenia, but no evidence of abnormal functioning in the pathway. ${ }^{16}$ This is the first article using FDT to detect this loss. Our findings coincide with the literature showing a decrease of M pathway function in schizophrenic patients (MD worse than relatives and control patients).

Another important point is that it has been suggested that early visual processing deficits are a risk factor for, or are an endophenotype of, schizophrenia, as opposed to an effect of the illness. ${ }^{31}$ Examination of the parents of schizophrenics allows for the identification of the genetic markers of schizophrenia in the absence of confounds that come with the study of the patients themselves, such as neuroleptic exposure, chronic hospitalization, or active symptom effects. ${ }^{2,3}$ In the present study, we found lower global sensitivity values in both schizophrenic patients and their parents compared with healthy controls. These could be a signal that there is a genetic correspondence to this visual field loss.

There is a relationship between the deficits in the parents and individuals with schizophrenia that can be inferred. Two articles have shown that schizophrenic patients and their firstdegree relatives have deficits in the gating of the P50 electrophysiological response to repeated stimuli. ${ }^{32,33}$ Deficits in the gating of the $\mathrm{P} 50$ response also appear in adolescents showing symptoms consistent with a heightened risk for imminent onset of psychosis. ${ }^{34} \mathrm{P} 50$ suppression is assessed using a

Table 2 Mean sensitivity values (MD) in the FDT test

\begin{tabular}{|c|c|c|c|c|}
\hline & $\begin{array}{l}\text { Healthy controls } \\
(n=12)\end{array}$ & $\begin{array}{l}\text { Parents } \\
(n=13)\end{array}$ & $\begin{array}{l}\text { Schizophrenic patients } \\
(n=13)\end{array}$ & $P$-value \\
\hline \multirow[t]{6}{*}{ Global FDT - MD } & $28.00(0.9 \mathrm{I})$ & $25.52(0.76)$ & $23.44(1.14)$ & Control vs schizophrenic \\
\hline & & & & $P=0.02$ \\
\hline & & & & Control vs parent \\
\hline & & & & $P=0.037$ \\
\hline & & & & Schizophrenic vs parent \\
\hline & & & & $P=0.129$ \\
\hline FDT - MD: decussating fibers & $28.25(0.87)$ & $25.70(0.80)$ & $23.56(1.18)$ & $P=0.910^{\dagger}$ \\
\hline FDT - MD: nondecussating fibers & $27.76(0.98)$ & $25.33(0.84)$ & $23.32(1.15)$ & \\
\hline FDT - MD: right hemisphere & $28.21(0.86)$ & $25.97(0.7 I)$ & $23.76(1.00)$ & $P=0.715^{\dagger}$ \\
\hline FDT - MD: left hemisphere & $27.86(0.91)$ & $25.14(0.90)$ & $23.18(1.31)$ & \\
\hline
\end{tabular}

Notes: The unit of measurement for MD is decibel (dB). MD = sensitivity of hemispheres. Data are presented as means, with standard deviations in parentheses. ${ }^{\dagger} P$ values are for interactions (fiber type $\times$ group and hemisphere $\times$ group).

Abbreviations: FDT, frequency doubling technology; MD, mean deviation. 


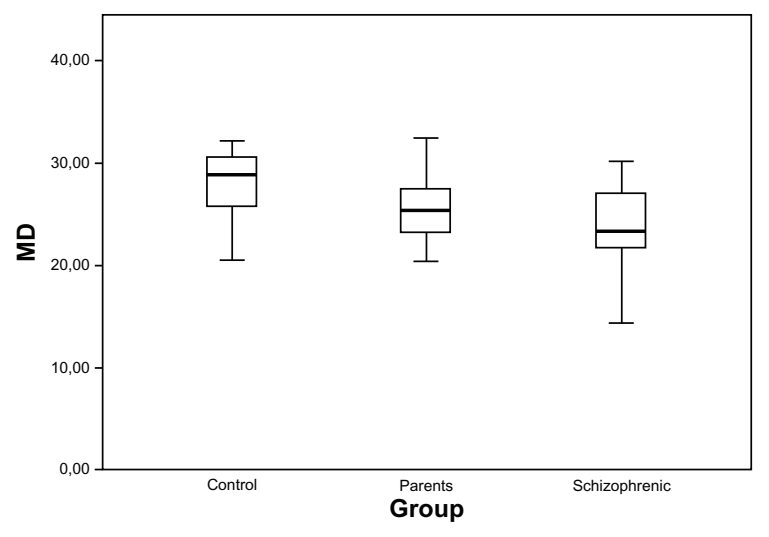

Figure I Distributions of general MD (in $\mathrm{dB}$ ) in healthy controls, parents, and schizophrenic patients, presented as box plots.

Abbreviation: MD, mean deviation.

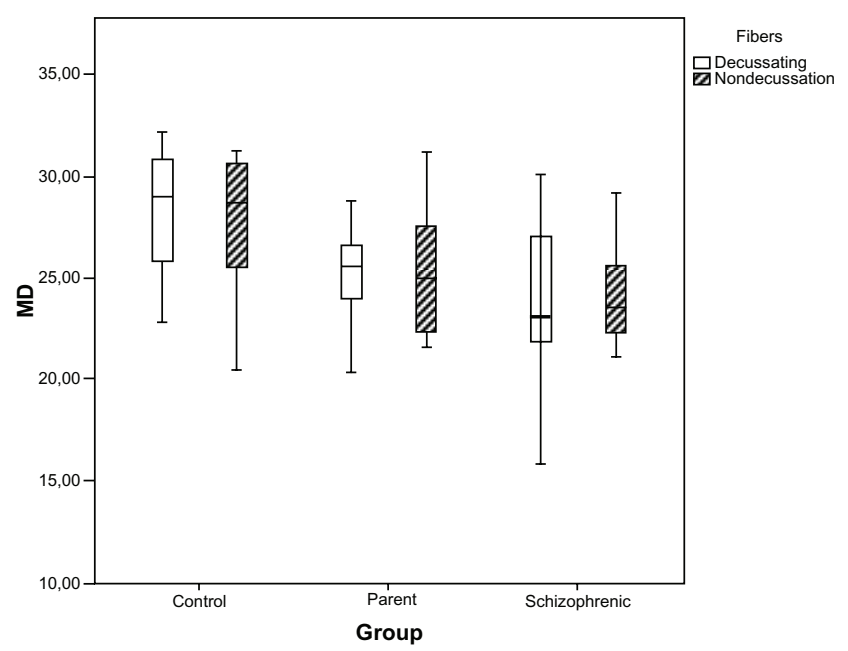

Figure 2 Distributions of $M D$ (in $\mathrm{dB}$ ) for the decussating and nondecussating fibers, in healthy controls, parents, and schizophrenic patients, presented as box plots. Abbreviation: MD, mean deviation.

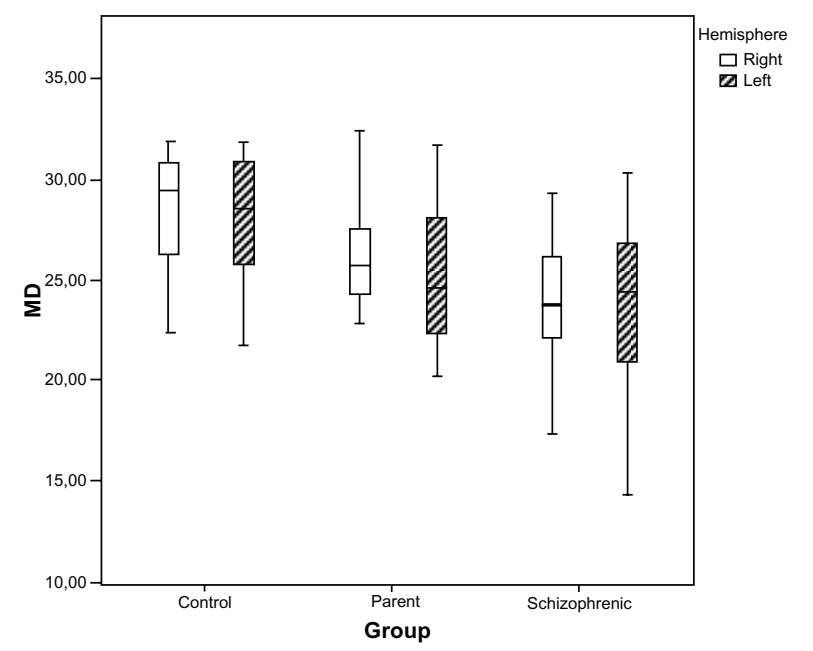

Figure 3 Distributions of the MD (in $\mathrm{dB}$ ) for the right and left hemispheres, in healthy controls, parents, and schizophrenic patients, presented as box plots. Abbreviation: MD, mean deviation. "paired-click" paradigm, in which two identical stimuli are separated by a brief interstimulus interval. P50 suppression refers to the reduction in P50 amplitude to the second stimuli relative to the first and is considered an index of the strength of "sensory gating." ${ }^{35}$ P50 suppression has been linked to chromosome loci, neurotransmitter systems, and anatomical structures implicated in the neuropathology of schizophrenia. ${ }^{36}$ This suppression deficit has been reported in at-risk individuals ${ }^{37}$ and unaffected first-degree relatives of schizophrenia probands, ${ }^{38}$ though heritability is evidenced to be lower than other endophenotype candidates. ${ }^{39}$

A hemispheric difference in schizophrenic patients has also been suggested. Hellige and Cumberland ${ }^{41}$ reported that there is some psychophysical evidence that the right hemisphere is more involved with processing $\mathrm{M}$ pathway information, such as spatial relationships, than is the left hemisphere. However, visual field researchers have tested this possibility using psychophysical methods and concluded that $\mathrm{M}$ pathway function is similar in both hemispheres. ${ }^{40} \mathrm{We}$ found a difference between the right and left hemispheres in the present study when the general MD was considered, but when we analyzed the MD in each group, we did not find any difference. Furthermore, analysis of the sensitivity of the fibers crossing the optic chiasm showed a difference, and this was the first time this has been seen in the literature.

The main clinical implication of our findings is that the $\mathrm{M}$ pathway deficit could affect the motion perception, for example. Of course, schizophrenic patients can have negative symptoms but these could be worsened by the visual field loss.

Some specific characteristics of our study should be considered. First, all schizophrenic patients were on antipsychotic treatment at the time of testing. In other words, all these patients were medicated and chronically ill. But no patient was acutely psychotic at the time of testing. Some visual functions, such as spatial contrast sensitivity, temporal sensitivity, and color vision, are controlled in part by dopamine. ${ }^{41}$ Since antipsychotic medications affect the dopaminergic system, we cannot ignore the possibility of a medication effect in our test results. Second, our sample was small because we had difficulty in identifying clinically controlled patients who were treated with the same drugs and who had available first-degree relatives. Third, there was a difference between the ages of the patients and controls and relatives. For obvious reasons, we cannot pair this variable and this may also have affected the outcome of the FDT. Lastly, the only exam used to detect visual field loss was FDT, but other exams such as optical coherence tomography 
(OCT) or Humphrey Visual Field analysis could also have been correlated; however, these could not have been used to isolate the $\mathrm{M}$ pathway.

In conclusion, we have found that schizophrenic patients and their parents exhibit lower global sensitivity as compared with healthy controls. This effect may be an endophenotype of schizophrenia and may be useful in future studies of the genetic markers of schizophrenia. The present study adds to a growing body of research on early-stage visual processing deficits in schizophrenia.

\section{Acknowledgments}

The authors express thanks to Aurea Garibaldi who provided a review of the grammar in the text.

\section{Disclosure}

The authors report no conflicts of interest in this work.

\section{References}

1. Goldman-Rakic PS. Working memory dysfunction in schizophrenia. J Neuropsychiatry Clin Neurosci. 1994;6(4):348-357.

2. Weinberger DR, Gallhofer B. Cognitive function in schizophrenia. Int Clin Psychopharmacol. 1997;12 Suppl 4:S29-S36.

3. Adler LE, Freedman R, Ross RG, Olincy A, Waldo MC. Elementary phenotypes in the neurobiological and genetic study of schizophrenia. Biol Psychiatry. 1999;46(1):8-18.

4. Braff DL, Saccuzzo DP, Geyer MA. Information processing dysfunctions in schizophrenia: studies of visual backward masking, sensorimotor gating, and habituation. In: Zubin J, Steinhauer S, Gruzelier JH, editors. Handbook of Schizophrenia; Neuropsychology, Psychophysiology and Information Processing. Amsterdam: Elsevier; 2010;4:303-334.

5. Javitt DC, Liederman E, Cienfuegos A, Shelley AM. Panmodal processing imprecision as a basis for dysfunction of transient memory storage systems in schizophrenia. Schizophr Bull. 1999;25(4):763-775.

6. Turetsky BI, Moberg PJ, Owzar K, Johnson SC, Doty RL, Gur RE. Physiologic impairment of olfactory stimulus processing in schizophrenia. Biol Psychiatry. 2003;53(5):403-411.

7. Green MF, Nuechterlein KH, Breitmeyer B. Backward masking performance in unaffected siblings of schizophrenic patients. Evidence for a vulnerability indicator. Arch Gen Psychiatry. 1997;54(5):465-472.

8. Skottun BC, Skoyles JR. On identifying magnocellular and parvocellular responses on the basis of contrast-response functions. Schizophr Bull. 2011;37(1):23-26.

9. Green MF, Butler PD, Chen Y, et al. Perception measurement in clinical trials of schizophrenia: promising paradigms from CNTRICS. Schizophr Bull. 2009;35(1):163-181.

10. Breitmeyer BG, Ganz L. Implications of sustained and transient channels for theories of visual pattern masking, saccadic suppression, and information processing. Psychol Rev. 1976;83(1):1-36.

11. Livingstone MS, Hubel DH. Psychophysical evidence for separate channels for the perception of form, color, movement, and depth. J Neurosci. 1987;7(11):3416-3468.

12. Bedwell JS, Miller LS, Brown JM, Yanasak NE. Schizophrenia and red light: fMRI evidence for a novel biobehavioral marker. Int $J$ Neurosci. 2006;116(8):881-894.

13. Butler PD, Schechter I, Zemon V, et al. Dysfunction of early-stage visual processing in schizophrenia. Am J Psychiatry. 2001;158(7): $1126-1133$.
14. Doniger GM, Foxe JJ, Murray MM, Higgins BA, Javitt DC. Impaired visual object recognition and dorsal/ventral stream interaction in schizophrenia. Arch Gen Psychiatry. 2002;59(11):1011-1020.

15. Foxe JJ, Doniger GM, Javitt DC. Early visual processing deficits in schizophrenia: impaired P1 generation revealed by high-density electrical mapping. Neuroreport. 2001;12(17):3815-3820.

16. Braus DF, Weber-Fahr W, Tost H, Ruf M, Henn FA. Sensory information processing in neuroleptic-naive first-episode schizophrenic patients: a functional magnetic resonance imaging study. Arch Gen Psychiatry. 2002;59(8):696-701.

17. Bedwell JS, Miller LS, Brown JM, McDowell JE, Yanasak NE. Functional magnetic resonance imaging examination of the magnocellular visual pathway in nonpsychotic relatives of persons with schizophrenia. Schizophr Res. 2004;71(2-3):509-510.

18. Kéri S, Kelemen O, Janka Z, Benedek G. Visual-perceptual dysfunctions are possible endophenotypes of schizophrenia: evidence from the psychophysical investigation of magnocellular and parvocellular pathways. Neuropsychology. 2005;19(5):649-656.

19. Gottesman II, GouldTD. The endophenotype concept in psychiatry: etymology and strategic intentions. Am J Psychiatry. 2003;160(4): 636-645.

20. Anderson AJ, Johnson CA. Frequency-doubling technology perimetry. Ophthalmol Clin North Am. 2003;16(2):213-225.

21. Cello KE, Nelson-Quigg JM, Johnson CA. Frequency doubling technology perimetry for detection of glaucomatous visual field loss. Am J Ophthalmol. 2000;129(3):314-322.

22. Kelly DH. Nonlinear visual responses to flickering sinusoidal gratings. J Opt Soc Am. 1981;71(9):1051-1055.

23. Richards W, Felton TB. Spatial frequency doubling: retinal or central? Vision Res. 1973;13(11):2129-2137.

24. White AJ, Sun H, Swanson WH, Lee BB. An examination of physiological mechanisms underlying the frequency-doubling illusion. Invest Ophthalmol Vis Sci. 2002;43(11):3590-3599.

25. Maddess T, Hemmi JM, James AC. Evidence for spatial aliasing effects in the Y-like cells of the magnocellular visual pathway. Vision Res. 1998;38(12):1843-1859.

26. Maddess T, James AC, Goldberg I, Wine S, Dobinson J. A spatial frequency-doubling illusion-based pattern electroretinogram for glaucoma. Invest Ophthalmol Vis Sci. 2000;41(12):3818-3826.

27. Sample PA, Bosworth CF, Blumenthal EZ, Girkin C, Weinreb RN. Visual function-specific perimetry for indirect comparison of different ganglion cell populations in glaucoma. Invest Ophthalmol Vis Sci. 2000;41(7):1783-1790.

28. Zeppieri M, Demirel S, Kent K, Johnson CA. Perceived spatial frequency of sinusoidal gratings. Optom Vis Sci. 2008;85(5):318-329.

29. McKendrick AM, Turpin A. Advantages of terminating Zippy Estimation by Sequential Testing (ZEST) with dynamic criteria for whiteon-white perimetry. Optom Vis Sci. 2005;82(11):981-987.

30. Asman P, Fingeret M, Robin A, et al. Kinetic and static fixation methods in automated threshold perimetry. J Glaucoma. 1999;8(5):290-296.

31. Green MF, Nuechterlein KH. Backward masking performance as an indicator of vulnerability to schizophrenia. Acta Psychiatr Scand Suppl. 1999;395:34-40.

32. Freedman R, Olincy A, Ross RG, et al. The genetics of sensory gating deficits in schizophrenia. Curr Psychiatry Rep. 2003;5(2):155-161.

33. Winterer G, Egan MF, Raedler T, et al. P300 and genetic risk for schizophrenia. Arch Gen Psychiatry. 2003;60(11):1158-1167.

34. Myles-Worsley M, Ord L, Blailes F, Ngiralmau H, Freedman R. P50 sensory gating in adolescents from a pacific island isolate with elevated risk for schizophrenia. Biol Psychiatry. 2004;55(7):663-667.

35. Freedman R, Adler LE, Waldo MC, Pachtman E, Franks RD. Neurophysiological evidence for a defect in inhibitory pathways in schizophrenia: comparison of medicated and drug-free patients. Biol Psychiatry. 1983;18(5):537-551.

36. Leonard S, Gault J, Hopkins J, et al. Association of promoter variants in the alpha7 nicotinic acetylcholine receptor subunit gene with an inhibitory deficit found in schizophrenia. Arch Gen Psychiatry. 2002;59(12):1085-1096. 
37. Cadenhead KS, Light GA, Geyer MA, Braff DL. Sensory gating deficits assessed by the P50 event-related potential in subjects with schizotypal personality disorder. Am J Psychiatry. 2000;157(1):55-59.

38. Clementz BA, Geyer MA, Braff DL. Poor P50 suppression among schizophrenia patients and their first-degree biological relatives. Am J Psychiatry. 1998;155(12):1691-1694.

39. Greenwood TA, Braff DL, Light GA, et al. Initial heritability analyses of endophenotypic measures for schizophrenia: the consortium on the genetics of schizophrenia. Arch Gen Psychiatry. 2007;64(11): 1242-1250.
40. Hellige JB, Cumberland N. Categorical and coordinate spatial processing: more on contributions of the transient/magnocellular visual system. Brain Cogn. 2001;45(2):155-163.

41. Djamgoz MB, Hankins MW, Hirano J, Archer SN. Neurobiology of retinal dopamine in relation to degenerative states of the tissue. Vision Res. 1997;37(24):3509-3529.
Clinical Ophthalmology

\section{Publish your work in this journal}

Clinical Ophthalmology is an international, peer-reviewed journal covering all subspecialties within ophthalmology. Key topics include: Optometry; Visual science; Pharmacology and drug therapy in eye diseases; Basic Sciences; Primary and Secondary eye care; Patien Safety and Quality of Care Improvements. This journal is indexed on

Submit your manuscript here: http://www.dovepress.com/clinical-ophthalmology-journal

\section{Dovepress}

PubMed Central and CAS, and is the official journal of The Society of Clinical Ophthalmology (SCO). The manuscript management system is completely online and includes a very quick and fair peer-review system, which is all easy to use. Visit http://www.dovepress.com/ testimonials.php to read real quotes from published authors. 